\title{
Multiparity Evaluation of Calving Ease and Stillbirth with Separate Genetic Effects by Parity
}

\author{
G. R. Wiggans, ${ }^{1}$ J. B. Cole, and L. L. M. Thornton \\ Animal Improvement Programs Laboratory, Agricultural Research Service, USDA, Beltsville, MD 20705-2350
}

\begin{abstract}
Evaluations that analyze first and later parities as correlated traits were developed separately for calving ease (CE) from over 15 million calving records of Holsteins, Brown Swiss, and Holstein-Brown Swiss crossbreds and for stillbirth (SB) from 7.4 million of the Holstein CE records. Calving ease was measured on a scale of 1 (no difficulty) to 5 (difficult birth); SB status was designated as live or dead within $48 \mathrm{~h}$. Scores for $\mathrm{CE}$ and SB were transformed separately for each trait by parity (first or later) and calf sex (male or female) and converted to a unit standard deviation scale. For variance component estimation, Holstein data were selected for the 2,968 bulls with the most records as sire or maternal grandsire (MGS). Six samples were selected by herd; samples ranged in size from 97,756 to 146,138 records. A multiparity sire-MGS model was used to calculate evaluations separately for $\mathrm{CE}$ and for SB with first and later parities as correlated traits. Fixed effects were year-season, calf sex, and sire and MGS birth years; random effects were herd-year interaction, sire, and MGS. For later parities, sex effects were separated by parity. The genetic correlation between first and later parities was 0.79 for sire and 0.81 for MGS for CE, and 0.83 for sire and 0.74 for MGS for SB. For national CE evaluations, which also include Brown Swiss, a fixed effect for breed was added to the model. Correlations between solutions on the underlying scale from the January 2008 USDA CE evaluation with those from the multiparity analysis for $\mathrm{CE}$ were 0.89 and 0.91 for first- and later-parity sire effects and 0.71 and 0.88 for first- and later-parity MGS effects; the larger value for later parity reflects that later parities comprised $64 \%$ of the data. Corresponding correlations for SB were 0.81 and 0.82 for first- and later-parity sire effects and 0.46 and 0.83 for first- and later-parity MGS effects, respectively. Correlations were higher when only bulls with a multiparity reliability of $>65 \%$ were
\end{abstract}

Received December 31, 2007.

Accepted April 23, 2008.

${ }^{1}$ Corresponding author: George.Wiggans@ars.usda.gov included. The multiparity analysis accounted for genetic differences in calving performance between first and later parities. Evaluations should become more stable as the portion of a bull's observations from different parities changes over his lifetime. Accuracy of the net merit index can be improved by adjusting weights to use evaluations for separate parities optimally.

Key words: calving trait, dystocia, stillbirth

\section{INTRODUCTION}

Calving traits affect the profitability of dairy production. Calving difficulty can reduce the productive life of the cow and decrease the survivability of the calf. Stillbirth (SB) reduces the size of the calf crop. Those traits are included in the net merit index (VanRaden and Multi-State Project S-1008, 2006) to reflect their impact on profitability.

In the United States, calving traits are currently evaluated as single traits across parity. Genetic evaluations for calving ease (CE) have been computed since 1977 (Berger, 1994; Van Tassell et al., 2003); national CE evaluations have been available for Holsteins since 1980 (Berger, 1994) and for Brown Swiss since 2005 (Cole et al., 2005). A sire-maternal grandsire (MGS) threshold model in which calvings for all parities were considered to be the same trait was introduced for CE in 2003 (Van Tassell et al., 2003; Wiggans et al., 2003). The same model is used for Holstein SB evaluations, which began in 2006 (Cole et al., 2007a,b).

Evaluations may be improved when calving traits are considered to be separate traits by parity (Klassen et al., 1990; Wiggans et al., 2006). The purpose of this study was to determine the genetic correlation between first and later parities for sire and MGS effects for CE and SB and to develop an evaluation system if correlations between parities showed that first and later parities are biologically distinct traits.

\section{MATERIALS AND METHODS}

\section{Data}

Calving ease scores were from 15,137,220 Holstein, 36,151 Brown Swiss, and 14,743 crossbred calving re- 
cords that were included in January 2008 USDA evaluations. The scores were reported on a 1 (no difficulty) to 5 (difficult birth) scale (Van Tassell et al., 2003). Of the Holstein CE records, 7,370,423 had SB scores recorded as 1 (live) or 2 (dead within $48 \mathrm{~h}$ of birth); the number of SB records available for Brown Swiss and crossbreds was insufficient for analysis (Cole et al., 2007a). First-parity records comprised $36 \%$ of the data for both CE and SB. Numbers of records are in Table 1 by original trait score, parity, calf sex, and breed.

With a threshold model, thresholds are estimated from the data and usually change the distance between scores. The CE and SB scores were transformed to a standard normal deviate across breeds within first or later parity and calf sex as described by Wiggans et al. (2006) to enable a linear model to approximate results from a threshold model. Each CE and SB score was set to the middle of the range between scores, and a constant for each trait was added to each score to make them all positive (Table 2). For both traits, the transformed score for a first-parity male birth with a score of 1 was 0.01 .

\section{Model}

A sire-MGS model was used to calculate evaluations separately for CE and SB with effects for first and later parities included as correlated traits. Fixed effects included year-season of calving ( 2 per year starting in April and October), calf sex, and sire and MGS birth years. For later parities, the effect for calf sex was divided by parity: parity 2 and parity $\geq 3$. For $\mathrm{CE}$, a breed effect was included (Holstein, Brown Swiss, and Brown Swiss $\times$ Holstein $F_{1}$ crossbred). Random effects were herd-year, sire, MGS, and residual. Birth year effects were included to capture trend in maternal granddams because the relationship matrix included only sire and MGS.

For variance component estimation, Holstein data were selected for the 2,968 bulls with the most calving records as either a sire or MGS. Six samples were selected by herd and ranged in size from 97,756 to 146,138 records. The program AIREMLF90 (Misztal et al., 2002) was used for variance component estimation. For both CE and SB, heritabilities for sire and MGS effects were estimated, and variance components were chosen from the sample that included estimates closest to the median.

The selected set of (co)variances was applied to calculate evaluations from all the data, including Brown Swiss and crossbred records. The same pedigree file for 145,208 bulls was used separately for CE and SB in the program BLUP90IOD2 (Misztal et al., 2002). Of those bulls, 49,230 were enrolled in genetic programs

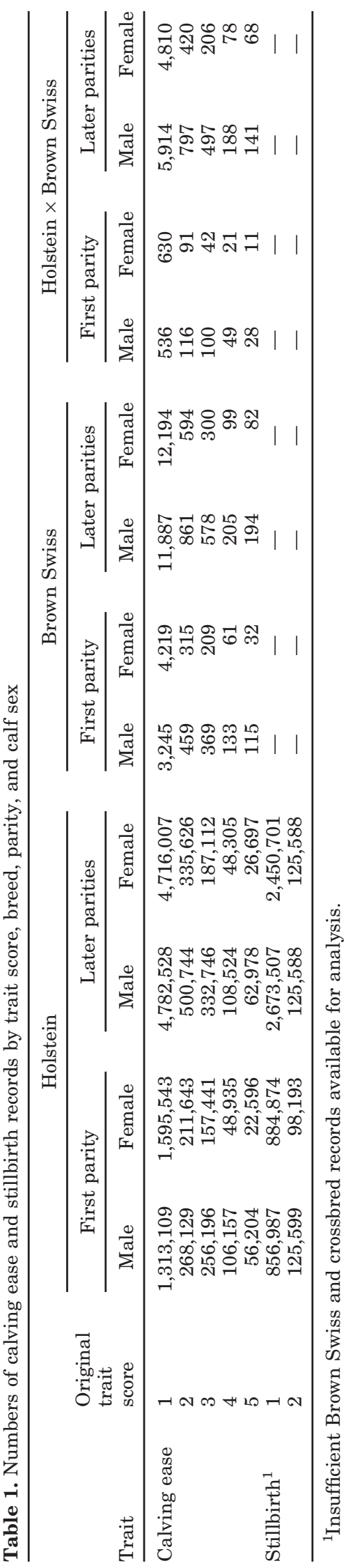


Table 2. Transformed scores for calving ease and stillbirth by parity and calf sex

\begin{tabular}{llccccc}
\hline & \multirow{2}{*}{$\begin{array}{l}\text { Original } \\
\text { trait } \\
\text { Trait }\end{array}$} & \multicolumn{2}{c}{ First parity } & & \multicolumn{2}{c}{ Later parities } \\
\cline { 3 - 4 } \cline { 6 - 7 } & score & Male & Female & & Male & Female \\
\hline Calving ease & 1 & 0.01 & 0.18 & 0.27 & 0.34 \\
& 2 & 1.02 & 1.40 & 1.62 & 1.90 \\
& 3 & 1.48 & 1.87 & 2.04 & 2.33 \\
& 4 & 2.04 & 2.44 & 2.53 & 2.83 \\
Stillbirth & 5 & 2.66 & 3.01 & 3.03 & 3.29 \\
& 1 & 0.01 & 0.05 & 0.10 & 0.11 \\
& 2 & 1.71 & 1.84 & 2.11 & 2.16 \\
\hline
\end{tabular}

of the National Association of Animal Breeders (Columbia, MO), and 955 were Brown Swiss. Reliabilities were calculated with the program ACCF90 (Strabel et al., 2001) as modified for sire-MGS models (Wiggans et al., 2008). Results on the underlying scale were compared with January 2008 results from the current threshold model (Van Tassell et al., 2003; Cole et al., 2005).

\section{RESULTS AND DISCUSSION}

Genetic correlations (Table 3$)$ of around 0.80 (0.79, CE sire; 0.81, CE MGS; 0.83, SB sire; and 0.74, SB MGS) indicate the potential benefit of considering firstand later-parity calvings as separate traits. Previous estimates of genetic correlations in dairy cattle for firstand later-parity calvings ranged from 0.52 to 0.63 for $\mathrm{CE}$ sire effects and from 0.74 to 0.90 for CE maternal effects (Jamrozik et al., 2005; Boelling et al., 2007); SB correlation estimates ranged from 0.38 to 0.62 for sire effects and from 0.31 to 0.60 for maternal effects (Jamrozik et al., 2005; Boelling et al., 2007). Some studies with dual-purpose and beef cattle (Carnier et al., 2000; Lee, 2002; Degano and Vicario, 2007) have reported higher genetic correlations for $\mathrm{CE}$, with some estimates that were close to 1 . Differences between dairy and beef cattle may reflect differences in population selection and management. Although this study's correlation estimates for CE and SB were higher than literature estimates for dairy cattle, they were still low enough to warrant evaluation of first and later parities as separate traits. The literature had indicated that maternal $\mathrm{CE}$ and SB should have first and later parities considered to be separate traits, and results of this study validated that conclusion with large data sets.

Table 4 shows heritability estimates and ranges for sire and MGS effects. The heritability estimates in the table are from the SB or CE sample that had the most estimates nearest the sample median. In most cases, the heritability estimate from that sample was nearest the median of the 6 samples. The MGS effect included both direct and maternal effects and, therefore, cannot be compared directly with purely maternal effects. Heritability estimates for $\mathrm{CE}$ were lower for later parities (0.03 for both sire and MGS effects) than for first parity (0.06 for sire effect; 0.08 for MGS effect); later-parity estimates for SB heritability also were lower $(<1 \%$ for both sire and MGS effects) than for first parity (0.04 for sire effect; 0.07 for MGS effect). Ranges were generally small, which indicated good agreement among samples. Previous estimates of heritability for first-parity CE ranged from 0.04 to 0.18 for sire effects (Cue et al., 1990; Groen et al., 1999; Jamrozik et al., 2005; Boelling et al., 2007) and from 0.05 to 0.14 for maternal effects (Cue and Hayes, 1985; Groen et al., 1999; Jamrozik et al., 2005; Boelling et al., 2007); later-parity heritabilities were more uniform and ranged from 0.02 to 0.08 for sire effects (Cue et al., 1990; Jamrozik et al., 2005; Boelling et al., 2007) and from 0.01 to 0.06 for maternal

Table 3. Genetic correlations between first- and later-parity sire and maternal grandsire (MGS) effects for calving ease and stillbirth

\begin{tabular}{|c|c|c|c|c|c|c|}
\hline \multirow[b]{2}{*}{ Trait } & \multirow[b]{2}{*}{ Effect } & \multirow[b]{2}{*}{ Parity } & \multicolumn{2}{|c|}{ Sire } & \multicolumn{2}{|c|}{ MGS } \\
\hline & & & First & Later & First & Later \\
\hline \multirow[t]{4}{*}{ Calving ease } & \multirow[t]{2}{*}{ Sire } & First & \multirow[t]{4}{*}{1.00} & 0.79 & 0.47 & 0.51 \\
\hline & & Later & & 1.00 & 0.57 & 0.75 \\
\hline & \multirow[t]{2}{*}{ MGS } & First & & & 1.00 & 0.81 \\
\hline & & Later & & & & 1.00 \\
\hline \multirow{4}{*}{ Stillbirth } & \multirow{2}{*}{ Sire } & First & \multirow[t]{4}{*}{1.00} & 0.83 & 0.07 & -0.20 \\
\hline & & Later & & 1.00 & 0.34 & 0.13 \\
\hline & \multirow{2}{*}{ MGS } & First & & & 1.00 & 0.74 \\
\hline & & Later & & & & 1.00 \\
\hline
\end{tabular}


Table 4. Heritabilities of sire and maternal grandsire ${ }^{1}$ (MGS) effects for first and later parities by calving trait

\begin{tabular}{llccccccc}
\hline & & \multicolumn{3}{c}{ First parity } & & \multicolumn{3}{c}{ Later parities } \\
\cline { 3 - 4 } Calving trait & Effect & Estimate & Median & Range & & Estimate & Median & Range \\
\hline Calving ease & Sire & 0.060 & 0.056 & 0.034 & & 0.033 & 0.0311 & 0.0152 \\
& MGS & 0.078 & 0.079 & 0.034 & & 0.030 & 0.0264 & 0.0135 \\
Stillbirth & Sire & 0.038 & 0.022 & 0.261 & & 0.004 & 0.0046 & 0.0002 \\
& MGS & 0.069 & 0.064 & 0.009 & & 0.006 & 0.0062 & 0.0007 \\
\hline
\end{tabular}

${ }^{1}$ The MGS effect includes both maternal and direct components and is not a true heritability.

effects (Cue et al., 1990; Groen et al., 1999; Jamrozik et al., 2005; Boelling et al., 2007). Previous SB studies (Jamrozik et al., 2005; Boelling et al., 2007) reported heritability estimates for sire effect from 0.02 to 0.04 for first parity and 0.01 for later parities; maternal SB estimates were 0.04 for first parity and ranged from 0.01 to 0.02 for later parities. For first-parity Danish Holsteins, Hansen et al. (2004) reported SB heritability estimates of 0.05 for sire effects and 0.06 for maternal effects from a linear model. The extremely low heritabilities for later-parity SB effects resulted from genetic variances that were 15 to 20 times smaller for later parities than for first.

Correlations between January 2008 evaluations from the USDA across-parity threshold model and multiparity linear model evaluations (Table 5) show that laterparity evaluations (correlations of $0.91, \mathrm{CE}$ sire; 0.88 , CE MGS; 0.83, SB sire; and 0.83, SB MGS) are more similar to January 2008 across-parity evaluations than are first-parity evaluations (correlations of $0.89, \mathrm{CE}$ sire; 0.71, CE MGS; 0.81, SB sire; and 0.46, SB MGS). That result is expected because of the preponderance $(64 \%)$ of later-parity records.
Corresponding correlations for bulls with an evaluation reliability of $>65 \%$ under the multiparity model (Table 5) were higher than for all bulls but generally support the same conclusions. Correlations between January 2008 across-parity and linear model evaluations for later-parity effects were 0.87 to 0.95 for bulls with a reliability of $>65 \%$, which indicates that large evaluation changes would not be expected; first-parity correlations were slightly lower (0.75 to 0.91$)$. Because calving difficulties are greatest for first parity, firstparity evaluations will be reported to the International Bull Evaluation Service (Uppsala, Sweden). The firstparity evaluations will be affected by later-parity observations through the correlations (Table 3). Evaluations for both first and later parities will be provided to bull owners and will be used in the net merit index. If the first-parity evaluation is the primary evaluation reported to producers, much of the change that they notice will result from excluding later-parity data. Because the linear model generates evaluations with the same interpretation as those from the threshold model, released evaluations will be converted to a probability

Table 5. Correlations between evaluations from a multiparity linear model and from the 2008 USDA acrossparity threshold model for calving ease and stillbirth by calving trait, model effect, parity, and reliability from the multiparity model

\begin{tabular}{|c|c|c|c|c|c|}
\hline Calving trait & Effect & Parity & $\begin{array}{c}\text { Reliability } \\
(\%)\end{array}$ & $\begin{array}{c}\text { Bulls } \\
\text { (no.) }\end{array}$ & Correlation \\
\hline \multirow[t]{8}{*}{ Calving ease } & \multirow[t]{4}{*}{ Sire } & \multirow[t]{2}{*}{ First } & All & 49,230 & 0.89 \\
\hline & & & $>65$ & 4,300 & 0.91 \\
\hline & & \multirow[t]{2}{*}{ Later } & All & 49,230 & 0.91 \\
\hline & & & $>65$ & 19,634 & 0.95 \\
\hline & \multirow{4}{*}{ MGS $^{1}$} & \multirow[t]{2}{*}{ First } & All & 49,230 & 0.71 \\
\hline & & & $>65$ & 8,121 & 0.79 \\
\hline & & \multirow[t]{2}{*}{ Later } & All & 49,230 & 0.88 \\
\hline & & & $>65$ & 13,416 & 0.91 \\
\hline \multirow[t]{8}{*}{ Stillbirth } & \multirow[t]{4}{*}{ Sire } & \multirow[t]{2}{*}{ First } & All & 48,275 & 0.81 \\
\hline & & & $>65$ & 1,929 & 0.88 \\
\hline & & \multirow[t]{2}{*}{ Later } & All & 48,275 & 0.83 \\
\hline & & & $>65$ & 1,755 & 0.93 \\
\hline & \multirow[t]{4}{*}{ MGS } & \multirow[t]{2}{*}{ First } & All & 48,275 & 0.46 \\
\hline & & & $>65$ & 2,484 & 0.75 \\
\hline & & \multirow{2}{*}{ Later } & All & 48,275 & 0.83 \\
\hline & & & $>65$ & 1,461 & 0.87 \\
\hline
\end{tabular}

\footnotetext{
${ }^{1}$ Maternal grandsire.
} 
Table 6. Mean reliability by parity for sire and maternal grandsire (MGS) effects and for January 2008 USDA evaluations for calving ease and stillbirth

\begin{tabular}{llccc}
\hline & & January 2008 & \multicolumn{2}{c}{ Parity } \\
\cline { 4 - 5 } Trait & Effect & USDA evaluations & First & Later \\
\hline Calving ease & Sire & 0.63 & 0.50 & 0.60 \\
\multirow{2}{*}{ Stillbirth } & MGS & 0.58 & 0.53 & 0.58 \\
& Sire & 0.45 & 0.39 & 0.40 \\
& MGS & 0.46 & 0.42 & 0.38 \\
\hline
\end{tabular}

scale as is currently done for USDA evaluations for calving traits (Wiggans et al., 2006).

Table 6 compares mean January 2008 bull reliabilities from the current threshold model with those from the multiparity linear model. Threshold reliabilities were calculated using only the diagonal of the coefficient matrix and are probably overestimates. The multiparity model provides reliabilities that are highly correlated with the true values from inversion of the coefficient matrix (Wiggans et al., 2008), which makes them more accurate than those from the threshold model. For CE, later-parity reliabilities were similar to those for January 2008 evaluations, and first-parity reliabilities were lower because of prediction with different heritabilities and fewer records. For SB, both first- and later-parity reliabilities were lower than January 2008 reliabilities because of heritability differences from across-parity heritability. The later-parity reliabilities are low because of the extremely low heritability estimate for later-parity $\mathrm{SB}$, which increases the number of records needed to achieve a given reliability. Comparison of reliabilities by birth year (not shown) showed the same trend for the threshold and 2 linear model reliabilities.

More comprehensive models were investigated: an animal model and including SB and CE in the same analysis. A single analysis was attractive because correlations of $\mathrm{SB}$ with $\mathrm{CE}$ would partially compensate for missing SB data, particularly for historical data. Problems in estimation of reasonable variance components led to retaining a sire-MGS model and not combining $\mathrm{CE}$ and $\mathrm{SB}$ in a single analysis. For current bulls, SB data generally are available; therefore, separate analysis by trait would not sacrifice much accuracy.

A Bayesian analysis using a multitrait threshold model and Gibbs samplings (Sorensen et al., 1995) also was examined. Convergence was extremely slow ( $>7 \mathrm{~d}$ for the national data set) and is not currently a feasible alternative for use in routine evaluation of $\mathrm{CE}$ and $\mathrm{SB}$.

\section{CONCLUSIONS}

Estimation of separate evaluations for calving traits by parity should increase evaluation accuracy because the genetic correlation between parities is $<1$. The separate effects should be more stable over time as the proportion of parities included in a bull's evaluation changes. Separate evaluations by parity should be particularly beneficial in assessing progeny-test bulls because later-parity calving traits would be specifically represented by parent information and first-parity information regressed by the correlation of $<1$. Differing economic impact of calving traits by parity can be accommodated in the net merit index.

\section{ACKNOWLEDGMENTS}

The authors thank M. A. Faust (ABS Global, DeForest, WI) for suggesting this area of research; M. T. Kuhn (Animal Improvement Programs Laboratory) for suggestions on the approach; and K. A. Weigel (University of Wisconsin, Madison) and S. M. Hubbard (Animal Improvement Programs Laboratory) for suggestions on manuscript improvement. Programs for estimation of variance components, breeding values, and reliabilities were provided by S. Tsuruta and I. Misztal (University of Georgia, Athens). The National Association of Animal Breeders (Columbia, MO) provided the data as part of its ongoing evaluation of calving traits.

\section{REFERENCES}

Berger, P. J. 1994. Genetic prediction for calving ease in the United States: Data, models, and use by the dairy industry. J. Dairy Sci. 77:1146-1153.

Boelling, D., U. Sander Nielsen, J. Pösö, J.-Å. Eriksson, and G. P. Aamand. 2007. Genetic evaluation of calving traits in Denmark, Finland and Sweden. Interbull Bull. 37:179-184.

Carnier, P., A. Albera, R. Dal Zotto, A. F. Groen, M. Bona, and G. Bittante. 2000. Genetic parameters for direct and maternal calving ability over parities in Piedmontese cattle. J. Anim. Sci. 78:2532-2539.

Cole, J. B., R. C. Goodling Jr., G. R. Wiggans, and P. M. VanRaden. 2005. Genetic evaluation of calving ease for Brown Swiss and Jersey bulls from purebred and crossbred calvings. J. Dairy Sci. 88:1529-1539.

Cole, J. B., G. R. Wiggans, and P. M. VanRaden. 2007a. Genetic evaluation of stillbirth in United States Holsteins using a sirematernal grandsire threshold model. J. Dairy Sci. 90:2480-2488.

Cole, J. B., G. R. Wiggans, P. M. VanRaden, and R. H. Miller. 2007b. Stillbirth (co)variance components for a sire-maternal grandsire threshold model and development of a calving ability index for sire selection. J. Dairy Sci. 90:2489-2496.

Cue, R. I., and J. F. Hayes. 1985. Correlations between calving ease and calf survival. J. Dairy Sci. 68:958-962.

Cue, R. I., H. G. Monardes, and J. F. Hayes. 1990. Relationships of calving ease with type traits. J. Dairy Sci. 73:3586-3590.

Degano, L., and D. Vicario. 2007. Genetic parameters for calving ease in Italian Simmental cattle. Ital. J. Anim. Sci. 6(Suppl. 1):117119.

Groen, A. F., J. P. J. M. van Aubel, and A. A. Hulzebosch. 1999. Calving performance in dairy cattle-Influence of maturity of dam on the correlation between direct and indirect effects. Stočarstvo 53:331-335.

Hansen, M., M. S. Lund, J. Pedersen, and L. G. Christensen. 2004. Genetic parameters for stillbirth in Danish Holstein cows using a Bayesian threshold model. J. Dairy Sci. 87:706-716. 
Jamrozik, J., J. Fatehi, G. J. Kistemaker, and L. R. Schaeffer. 2005. Estimates of genetic parameters for Canadian Holstein female reproduction traits. J. Dairy Sci. 88:2199-2208.

Klassen, D. J., R. I. Cue, and J. F. Hayes. 1990. Estimation of repeatability of calving ease in Canadian Holsteins. J. Dairy Sci. 73:205-212.

Lee, D. H. 2002. Estimation of genetic parameters for calving ease by heifers and cows using multi-trait threshold animal models with Bayesian approach. Asian-australas. J. Anim. Sci. 15:1085-1090.

Misztal, I., S. Tsuruta, T. Strabel, B. Auvray, T. Druet, and D. H. Lee. 2002. BLUPF90 and related programs. Proc. 7th World Congr. Genet. Appl. Livest. Prod. 33:743-744.

Sorensen, D., S. Andersen, D. Gianola, and I. Korsgaard. 1995. Bayesian inference in threshold models using Gibbs sampling. Genet. Sel. Evol. 27:229-249.

Strabel, T., I. Misztal, and J. K. Bertrand. 2001. Approximation of reliabilities for multiple-trait model with maternal effects. J. Anim. Sci. 79:833-839.
Van Tassell, C. P., G. R. Wiggans, and I. Misztal. 2003. Implementation of a sire-maternal grandsire model for evaluation of calving ease in the United States. J. Dairy Sci. 86:3366-3373.

VanRaden, P. M., and Multi-State Project S-1008. 2006. Net merit as a measure of lifetime profit: 2006 revision. http://aipl.arsusda.gov/ reference/nmcalc-2006.htm Accessed Dec. 28, 2007.

Wiggans, G. R., I. Misztal, and C. P. Van Tassell. 2003. Calving ease (co)variance components for a sire-maternal grandsire threshold model. J. Dairy Sci. 86:1845-1848.

Wiggans, G. R., S. Tsuruta, and I. Misztal. 2008. Technical note: Adaptation of an animal-model method for approximation of reliabilities to a sire-maternal grandsire model. J. Dairy Sci. 91: doi:10.3168/jds.2007-0955. (accepted)

Wiggans, G. R., C. P. Van Tassell, J. B. Cole, and L. L. M. Thornton. 2006. Genetic correlations between first and later parity calving ease in a sire-maternal grandsire model. Proc. 8th World Congr. Genet. Appl. Livest. Prod., CD-ROM Comm. 01-92. 